\title{
In silico characterization of Echinococcus granulosus paramyosin nucleotide sequence for the development of epitope vaccine against cystic echinococcosis
}

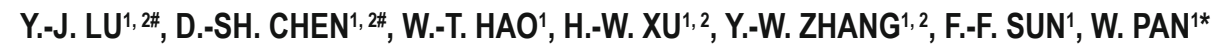

\begin{abstract}
1 Jiangsu Key Laboratory of Immunity and Metabolism, Department of Pathogenic Biology and Immunology, Laboratory of Infection and

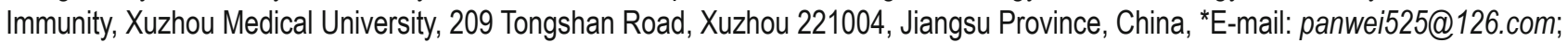

2Department of Clinical Medicine, Xuzhou Medical University, 209 Tongshan Road, Xuzhou 221004, Jiangsu Province, China
\end{abstract}

Article info

Received November 30, 2016 Accepted June 29, 2017

\begin{abstract}
Summary
The paramyosin (Pmy) protein has been presented as a potential vaccine candidate against Schistosoma spp. However, it remains elusive whether it works in controlling cystic echinococcosis (CE), which is caused by the larval stages of Echinococcus granulosus (E. granulosus). This study investigated the characteristics of $E$. granulosus Pmy (EgPmy) using in silico analysis and evaluated its potential as an epitope vaccine. The secondary structure was predicted by SOPMA software and linear B-cell epitopes were screened by the Kolaskar and Tongaonkar's method on IEBD while conformational B-cell epitopes were predicted by the Ellipro. Additionally, the epitopes of cytotoxic T lymphocyte (CTL) were analyzed by the NetCTL-1.2 server. The results showed that a-helices, extended strands, random coils and $\beta$-turns accounted for $84.82 \%, 6.60 \%, 5.56 \%$ and $3.01 \%$ in EgPmy's secondary structure, respectively. A total of 29 linear B-cell epitopes and 6 conformational epitopes were identified together with 25 CTL epitopes. The CTL epitope ${ }^{709 K L E E A E A F A}{ }^{717}$ showed a high potential to elicit CTL response. These results suggested that EgPmy has a strong immunogenicity, which could serve as a reference for the development of EgPmy-based epitope vaccine against CE.
\end{abstract}

Keywords: Echinococcus granulosus; paramyosin; antigen epitope; vaccine; bioinformatics

\section{Introduction}

Cystic echinococcosis (CE) is a zoonotic disease caused by infection with the larval stages of Echinococcosis granulosus (E. granulosus). It has a worldwide distribution including Asia, Africa, Europe and North American (Eckert et al., 2000; Nunnari et al., 2012). In China, it is mainly endemic in pasture areas such as Tibet, Xinjiang, Gansu, Qinghai, Ningxia and semi-pasture areas. The disease does great harm to human health and the development of the local economy (Yang et al., 2015). At present, many actions have been taken to treat this disease, during which surgery in combination with medications remains the first choice. However, it inevitably entails surgical risk and requires considerable labour, material, and financial resources (Nasrieh et al., 2003). Moreover, surgery often causes inevitable damage to human body and the secondary infection rate is still high. Therefore, it is still necessary to seek high-efficiency treatment measures to control the disease. In recent years, immunoprophylaxis has become the dominant way to prevent and control echinococcosis and the advances in vaccine development have been documented. A study by Lightowlers et al. (1996) revealed that the Eg95 recombinant antigen induced a $95-100 \%$ protective immune effect against oncosphere infection in sheep. Siles et al. (2003) used the Em14-3-3 recombinant protein to vaccinate mice infected by the eggs of Echinococcus multilocularis (E. multilocularis), reducing the number of liver lesions in vaccinated animals from 43 to 1 mean lesion per animal.

\footnotetext{
$\bar{*}$ - corresponding author

\#- These authors contributed equally to this work.
} 
Additionally, the Emy162 recombinant antigen showed a $74.3 \%$ protective rate in rats against $E$. multilocularis (Kouguchi et al., 2011) and a vaccine against this parasite based on the Em95 protein, with a protective efficiency of $78.5-82.9 \%$, was developed by Katoh et al (2008). These results suggested that it is feasible and efficient to prevent echinococcosis by developing molecular vaccines.

Paramyosin (Pmy) is a structural protein in invertebrate muscles (Cohen, 1982), which involves in muscle physiological contraction and immune-regulation (Gobert \& McManus, 2005). Interestingly, it has been demonstrated to be a promising vaccine candidate for controlling the infections of both Schistosoma japonicum (S. japonicum) and S. mansoni (Jiz et al., 2015). Also, a study by Nanduri et al. (1989) revealed that immunizing mice with the Caenorhabditis elegans paramyosin protects against Brugia malayi challenge with an immune protective effect of up to $60 \%$. Moreover, Vazquez et al. (2001) discovered that the parasite load in mice infected with Taenia solium ( $T$. solium) larvae is reduced by approximately $52 \%$ by immunizing mice with the total length of $T$. solium recombinant paramyosin. In addition, Ferrer et al. (2003) reported that the $T$. saginata paramyosin was highly recognized by antibodies in $100 \%$ of the sera collected from patients with acute cysticercosis. However, little information is known about their protection efficiency as vaccines against CE. The finding attracts us to study the protection role of $E$. granulosus Pmy (EgPmy) against the parasite infection, since that EgPmy shares a high identity to that of $S$. mansoni, and is also expressed in the tegument of the larval cestode (Mühlschlegel et al., 1993). Previous studies have suggested that the protein was relevant to immuno-regulatory events at the host-parasite interface and the detection of its IgG4 was found to show a good diagnostic potential of human hydatidosis (Monteiro et al., 2010; Moghadam et al., 2013). What's more, EgPmy was reported to share some sequence elements and properties with EgA31, the latter protein was demonstrated to induce a high efficient protection against $E$. granulosus infection in dogs (Petavy et al., 2008). Overall, these results implied a potential of EgPmy to be an immunogen and vaccine target against $C E$.

With the advance of bioinformatics technology, the epitope vaccine has become a hot area in vaccine development (Ben \& Arnon, 2005; Pfaff et al., 1988; Toussaint \& Kohlbacher, 2009; Zieglmayer et al., 2016; Oyarzún \& Kobe, 2016). Compared to traditional vaccines, epitope vaccines have the ability to stimulate an effective specific immune response with a minimal structure, while avoiding undesirable effects (Ben \& Arnon, 2005). Considering that EgPmy is a macromolecular protein with $97-\mathrm{kDa}$ (Cohen, 1982), a minimal molecular weight with the main immunogenic epitopes of EgPmy, should induce a more specific antibody response but less side effects. However, it is still unclear whether the EgPmy could be developed to design an epitope vaccine. In this study, we used in silico analysis to characterize the secondary structure, the B-cell and CTL epitopes in EgPmy, which would provide the theoretical foundation for developing EgPmy-based epitope vaccine.

\section{Materials and Methods}

\section{Protein sequence retrieval}

The nucleotide sequence of EgPmy was retrieved from GenBank (GenBank No. Z21787). A total of 863 amino acid residues were predicted in EgPmy protein, and were then used as an template for analyzing its antigenicity, secondary structure, as well as epitopes. The amino acid sequence of EgPmy was shown in Supplementary Fig. 1.

\section{Structural analysis}

Various parameters for EgPmy, including the molecular weight, theoretical pl, atomic composition, instability index, aliphatic index and grand average of hydropathicity (GRAVY), were predicted by the ProtParam (http://web.expasy.org/protparam/) (Gasteiger et al., 2005). To determine its antigenicity, the parameters of the secondary structure that include $\alpha$-helices, extended strands, $\beta$-turns and random coils, were analyzed by the improved self-optimized prediction method (SOPMA) software (http://npsa-pbil.ibcp.fr/ cgi-bin/npsa_automat.pl?page=npsa_sopma.html) (Geourjon \& Deléage, 1995). The protein sequence was input, and the parameters of similarity threshold and window width were set to 8 and 17 , respectively, while other parameters were not adjusted.

\section{$B$-cell epitope prediction}

Linear B-cell epitopes of EgPmy were predicted at the Immune Epitope Database (IEDB: http://tools.immuneepitope.org/bcell/) online software (Vita et al., 2010) using the method of Kolaskar and Tongaonkar (Kolaskar \& Tongaonkar, 1990), which is based on the occurrence of amino acid residues in experimentally determined epitopes. The method was applied to predict antigenic determinants on a large number of proteins with about $75 \%$ accuracy, which is much better than most of the known methods (Kolaskar \& Tongaonkar, 1990). Moreover, Emini's method (Emini et al., 1985) was used for surface accessibility prediction while Karplus and Schulz's algorithm (Vihinen et al., 1994) for flexibility determination. Conformational B-cell epitopes based on the protein antigen's 3D structure were predicted by an online tool Ellipro (http://tools.immuneepitope.org/ellipro/) (Ponomarenko et al.,

Table 1. Secondary structural characteristics of EgPmy (Genbank no.Z21787)

\begin{tabular}{ll}
\hline Criteria & Assessment \\
\hline Number of amino acids & 863 \\
Molecular weight & $98741.4 \mathrm{Da}$ \\
Theoretical pl & 5.21 \\
Formula & $\mathrm{C}_{4163} \mathrm{H}_{6985} \mathrm{~N}_{1299} \mathrm{O}_{1423} \mathrm{~S}_{23}$ \\
Instability index & 47.70 \\
Aliphatic index & 84.99 \\
Grand average of hydropathicity & -0.897 \\
(GRAVY) & \\
\hline
\end{tabular}




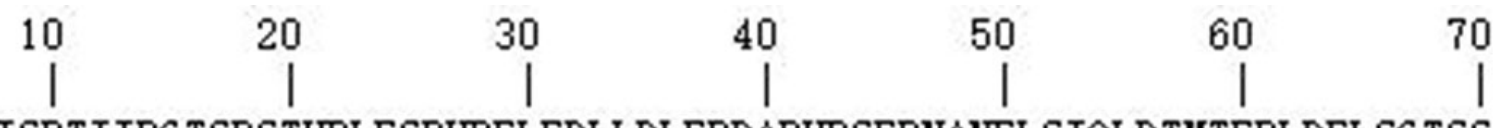

MSESHVK ISRT IIRG TSPSTVRLESPVRELEDLLDLERDARVRSERNANELSIQLDTMTERLDELSGTSS

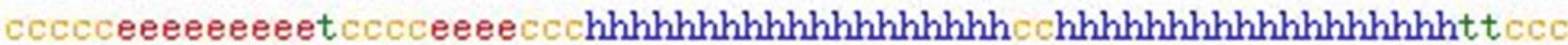
QTQDAIRRKDMEIANVRKDLENANAAFETAEATLRRKHNTMISEISSEVENLQKQKGRAEKDKSQLMLEI

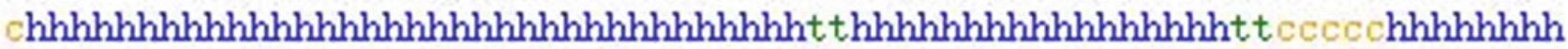
DNULGQLDGALKAKASAESKLEGLDSQL TRLKAL TDDLQRQMADVNSAKSRLAAENFEL VRVNQEYEAQV

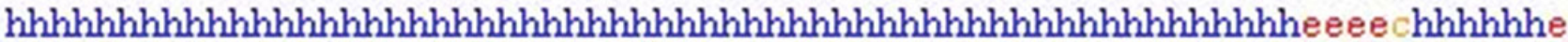
VNFSK TKSVLEGQLDDLKRAMDEDARNRLNLQTQLSSLQIDYDNLQARYEEEAEABGMLRNQVAKFNADM

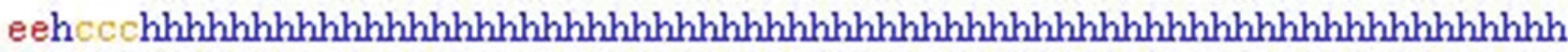
AALK TRLERELMAK TEEFEELKRKL TVRI TELED IAEHERTRANRLEK TKVKL T IE IKDLQAENEALASE

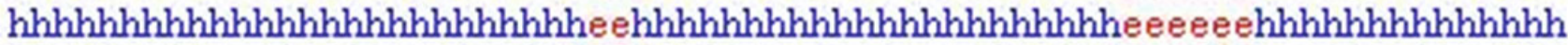
NGEL THRAKQAENLANELQRRVDETVE INTLNSANNALEGDNMRLKGQVGDL TDRIANLDRENRQLGDQ

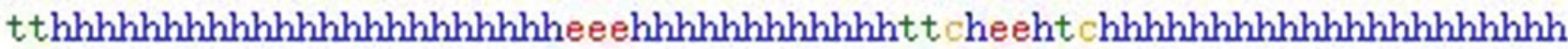
LKETKSALRDANRRL TDLEALRSQLEADGDNLASALHDAEEALKELEVKYVASQNALNHLKSEMEQRLRE

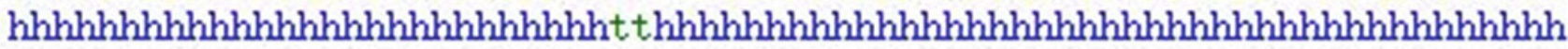
KDEELENLRKST TRT IEEL TT T ISEMEVRFKSDMSRLKKKYEAT ISELEVQLDVANKANASLNRENKALA

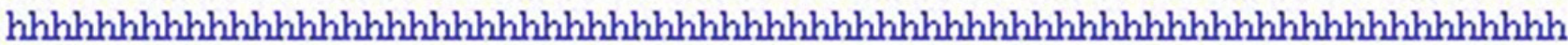
QRVQELQTALEDERRAREASESNLQVSERKRIAL TSEVEEIRSQLELSDRARKNAESELNDANGRISELT

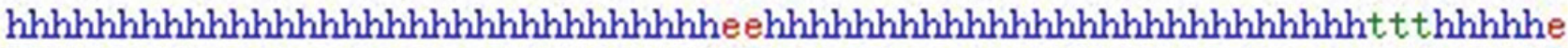
MSVNL TNDKRRLEGDIGVMQGDLDEAVNARKAAEDRADRLNAEVLRLADELRQEQENYRAETLRKQLE

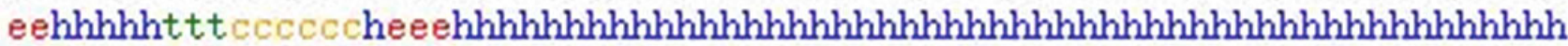
IEIREITVKLEEAEAFATREGRRVQKLQNRVRELEAELDGEIRRAKEAFASARKYERQFKELQTQSEDD

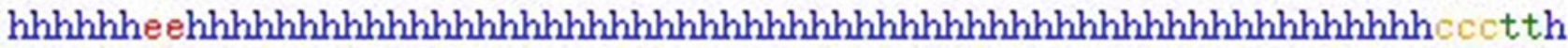
KRMILELQDLLDK TQIKMKAYKRQLEEQEEVSQL TMSKYRKAQQQIEEAEHRADMAERT IT IKRT IGGPG

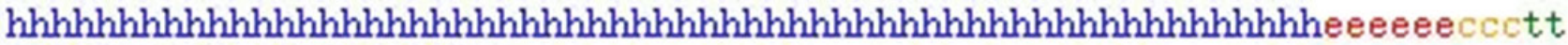
SRAVSWREINSWSRGNRATSIM

cceeeehhhhhhcttcccceee

Sequence length : 863

Fig. 1. Secondary structure of EgPmy using SOPMA analysis.

2008). The input file of EgPmy to the online tool was provided in $\mathrm{PDB}$ format and the minimum score value was set at 0.7 while the maximum distance was selected as $6 \AA$.

\section{CTL epitopes prediction}

CTL epitope prediction was carried out using the NetCTL.1.2 server (http://www.cbs.dtu.dk/services/NetCTL) (Larsen et al., 2007). The method combines the prediction of peptide major histocompatibility complex (MHC) class I binding, proteasomal $\mathrm{C}$ terminal cleavage and T cell activating protein (TAP) transport efficiency. $\mathrm{MHC}$ class I binding and proteasomal cleavage are performed using artificial neural networks and TAP transport efficiency is predicted using weight matrix (Larsen et al., 2007). The input file for
EgPmy was provided with the protein sequence and the parameter of $\mathrm{MHC}$ class I supertype was selected as $\mathrm{A} 2$. The remaining parameters were not altered. Therefore, the IEDB online prediction software (http://tools.immuneepitope.org//mmunogenicity/) (Calis et al., 2013) was applied to predict the immunogenicity of the candidate epitopes. This tool uses amino acid properties as well as their position within the peptide to predict the immunogenicity of a peptide-MHC (pMHC) complex (Calis et al., 2013).

Results

Structure characteristics

To understand the antigenic features, the secondary structural 
characteristics of EgPmy were analyzed firstly. It included total length of 863aa, with a molecular weight of $98741.4 \mathrm{Da}$, theoretical pl of 5.21, formula of $\mathrm{C}_{4163} \mathrm{H}_{6985} \mathrm{~N}_{1299} \mathrm{O}_{1423} \mathrm{~S}_{23}, 732$ a-helices, 57 extended strands, $26 \beta$-turns and 48 random coils (shown in Table 1 and Fig. 1). The grand average of GRAVY was predicted to be negative $(-0.897)$. This showed that the protein has a good hydrophilicity and most of the residues are located on the surface, which are likely to bind residues when interacting with other proteins (Kyte \& Doolittle, 1982).

\section{$B$-cell epitopes identification}

The identification of B-cell epitope is one of the key steps in the development of an epitope vaccine. This study predicted the B-cell epitopes of EgPmy using the IEDB software, and EgPmy was found to contain 29 linear B-cell epitopes. Their length ranged from 6 to 20 amino acids with 6 octapeptides and 7 heptapeptides. The epitope length, sequences and locations, were shown in Table 2 . The antigenic propensity varied along the sequence length, and the average antigenic propensity value of these epitopes was 0.992 with a minimum of 0.868 and a maximum of 1.159 (Supplementary Fig. 2).

Moreover, surface accessibility and fragment flexibility, the important features of B-cell eptitopes, were also analyzed by IEDB database. According to Emini's method, the maximum surface accessibility value of the predicted epitopes was 5.287 from amino acid position 754 to 759 for EgPmy. The sequence of the hexapeptide was ${ }^{754} \mathrm{RKYERQ}^{759}$, where $756 \mathrm{Y}$ was the surface residue. The minimum surface accessibility value was 0.123 from amino

Table 2. Predicted linear B-cell epitopes of EgPmy using the Kolaskar and Tongaonkar's method on IEDB software.

\begin{tabular}{|c|c|c|c|c|}
\hline No. & Start Position & End Position & Peptide & Peptide Length \\
\hline 1 & 4 & 11 & SHVKISRT & 8 \\
\hline 2 & 18 & 37 & PSTVRLESPVRELEDLLDLE & 20 \\
\hline 3 & 114 & 122 & EISSEVENL & 9 \\
\hline 4 & 135 & 154 & QLMLEIDNVLGQLDGALKAK & 20 \\
\hline 5 & 161 & 177 & LEGLDSQLTRLKALTDD & 17 \\
\hline 6 & 194 & 203 & AENFELVRVN & 10 \\
\hline 7 & 207 & 214 & EAQVVNFS & 8 \\
\hline 8 & 216 & 227 & TKSVLEGQLDDL & 12 \\
\hline 9 & 241 & 250 & LQTQLSSLQM & 10 \\
\hline 10 & 270 & 276 & RNQVAKF & 7 \\
\hline 11 & 303 & 310 & RKLTVRIT & 8 \\
\hline 12 & 328 & 340 & KTKVKLTIEIKDL & 13 \\
\hline 13 & 397 & 403 & KGQVGDL & 7 \\
\hline 14 & 437 & 444 & DLEALRSQ & 8 \\
\hline 15 & 453 & 460 & ASALHDAE & 8 \\
\hline 16 & 463 & 480 & LKELEVKYVASQNALNHL & 18 \\
\hline 17 & 532 & 545 & EATISELEVQLDVA & 14 \\
\hline 18 & 558 & 569 & ALAQRVQELQTA & 12 \\
\hline 19 & 582 & 587 & SNLQVS & 6 \\
\hline 20 & 591 & 608 & RIALTSEVEEIRSQLELS & 18 \\
\hline 21 & 629 & 635 & LTMSVNT & 7 \\
\hline 22 & 672 & 681 & NAEVLRLADE & 10 \\
\hline 23 & 705 & 711 & EITVKLE & 7 \\
\hline 24 & 725 & 732 & VQKLQNRV & 8 \\
\hline 25 & 749 & 754 & AFASAR & 6 \\
\hline 26 & 774 & 784 & ILELQDLLDKT & 11 \\
\hline 27 & 800 & 807 & EVSQLTMS & 8 \\
\hline 28 & 810 & 816 & RKAQQQI & 7 \\
\hline 29 & 841 & 853 & SRAVSVVREINSV & 13 \\
\hline
\end{tabular}


acid position 645 to 650 . The sequence of the hexapeptide was ${ }^{645} \mathrm{GDIGVM}^{650}$, where 647 I was the surface residue (Supplementary Fig. 3). On the other hand, the result of the flexibility prediction showed that the maximum value of the flexibility was 1.142 from amino acid position 67 to 72 for EgPmy. The sequence of the heptapeptide was ${ }^{67} \mathrm{GTSSQTQ}{ }^{72}$, where $70 \mathrm{~S}$ was the flexibility residue. The minimum flexibility value was 0.917 from amino acid position 277 to 283 and its sequence of the heptapeptide was
${ }^{277} \mathrm{NADMAAL}^{283}$, where $280 \mathrm{M}$ was the flexibility residue (Supplementary Fig. 4).

In addition, 6 conformational B-cell epitopes were obtained by the ElliPro with a score defined as a Protrusion Index (PI) value over 0.7 . The highest probability of a conformational epitope was calculated at 98.7 \% (PI score: 0.987). Conformational epitopes' residues, their sequence location, number of residues and scores were given in Table 3 .

Table 3. Predicted conformational B-cell epitopes of EgPmy using the Ellipro.

\begin{tabular}{|c|c|c|c|}
\hline No. & Residues and their Positions & $\begin{array}{l}\text { Number of } \\
\text { Residues }\end{array}$ & Score \\
\hline 1 & $\begin{array}{l}\text { R848, E849, I850, N851, S852, V853, S854, R855, G856, } \\
\text { N857, R858, A859, T860, S861, I862, M863 }\end{array}$ & 16 & 0.987 \\
\hline 2 & M1, S2, E3, S4, H5, V6, K7, I8, S9, R10, T11, I12, I13, R14 & 14 & 0.813 \\
\hline 3 & $\begin{array}{l}\text { R22, L23, E24, S25, P26, V27, R28, E29, L30, E31, D32, L33, } \\
\text { L34, D35, L36, E37, R38, D39, A40, R41, V42, R43, S44, E45, } \\
\text { R46, N47, A48, N49, E50, L51, S52, I53, Q54, L55, D56, T57, } \\
\text { M58, T59, E60, R61, L62, D63, E64, L65, S66, G67, T68, S69, } \\
\text { S70, T72, Q73, D74, I76, R78, K79, D80, M81, E82, I83, A84, } \\
\text { N85, V86, R87, K88, D89, L90, E91, N92, A93, N94, A95, A96, } \\
\text { F97, E98, T99, A100, E101, A102, T103, L104, R105, R106, } \\
\text { K107, H108, N109, T110, M111, I112, S113, E114, I115, S116, } \\
\text { S117, E118, E130 }\end{array}$ & 95 & 0.786 \\
\hline 4 & $\begin{array}{l}\text { V732, R733, E734, L735, E736, A737, E738, L739, D740, } \\
\text { G741, E742, I743, R745, A746, K747, E768, D769, D770, } \\
\text { K771, R772, M773, I774, L775, E776, L777, Q778, D779, } \\
\text { L780, L781, D782, K783, T784, Q785, I786, K787, M788, } \\
\text { K789, A790, Y791, K792, R793, Q794, L795, E796, E797, } \\
\text { Q798, E799, E800, V801, S802, Q803, L804, T805, M806, } \\
\text { S807, K808, Y809, R810, K811, A812, Q813, Q814, Q815, } \\
\text { l816, E817, E818, A819, E820, H821, R822, A823, D824, } \\
\text { M825, A826, E827, R828, T829, I830, T831, I832, K833, T835, } \\
\text { I836, G837, G838, P839, G840, S841, R842, A843, V844, } \\
\text { S845, V846, V847 }\end{array}$ & 94 & 0.753 \\
\hline 5 & $\begin{array}{l}\text { G398, Q399, V400, G401, D402, L403, T404, D405, R406, } \\
\text { I407, A408, N409, L410, D411, R412, E413, N414, R415, A431, } \\
\text { N432, R433, R434, L435, T436, D437, E439, A440, L441, } \\
\text { R442, S443, Q444, L445, E446, A447, D448, G449, D450, } \\
\text { N451, L452, A453, S454, A455, L456, H457, D458, A459, } \\
\text { E460, E461, A462, L463, K464, E465, L466, E467, V468, } \\
\text { K469, Y470, V471, A472, S473, Q474, N475, A476 }\end{array}$ & 63 & 0.741 \\
\hline 6 & $\begin{array}{l}\text { S214, K215, T216, K217, S218, V219, L220, E221, G222, } \\
\text { Q223, L224, D225, D226, L227, K228, K613, N614, A615, } \\
\text { E616, S617, E618, L619, N620, D621, A622, N623, G624, } \\
\text { R625, I626, S627, E628, L629, T630, M631, A679, D680, } \\
\text { E681, L682, R683, Q684, E685, Q686, E687, N688, Y689, } \\
\text { K690 }\end{array}$ & 46 & 0.707 \\
\hline
\end{tabular}




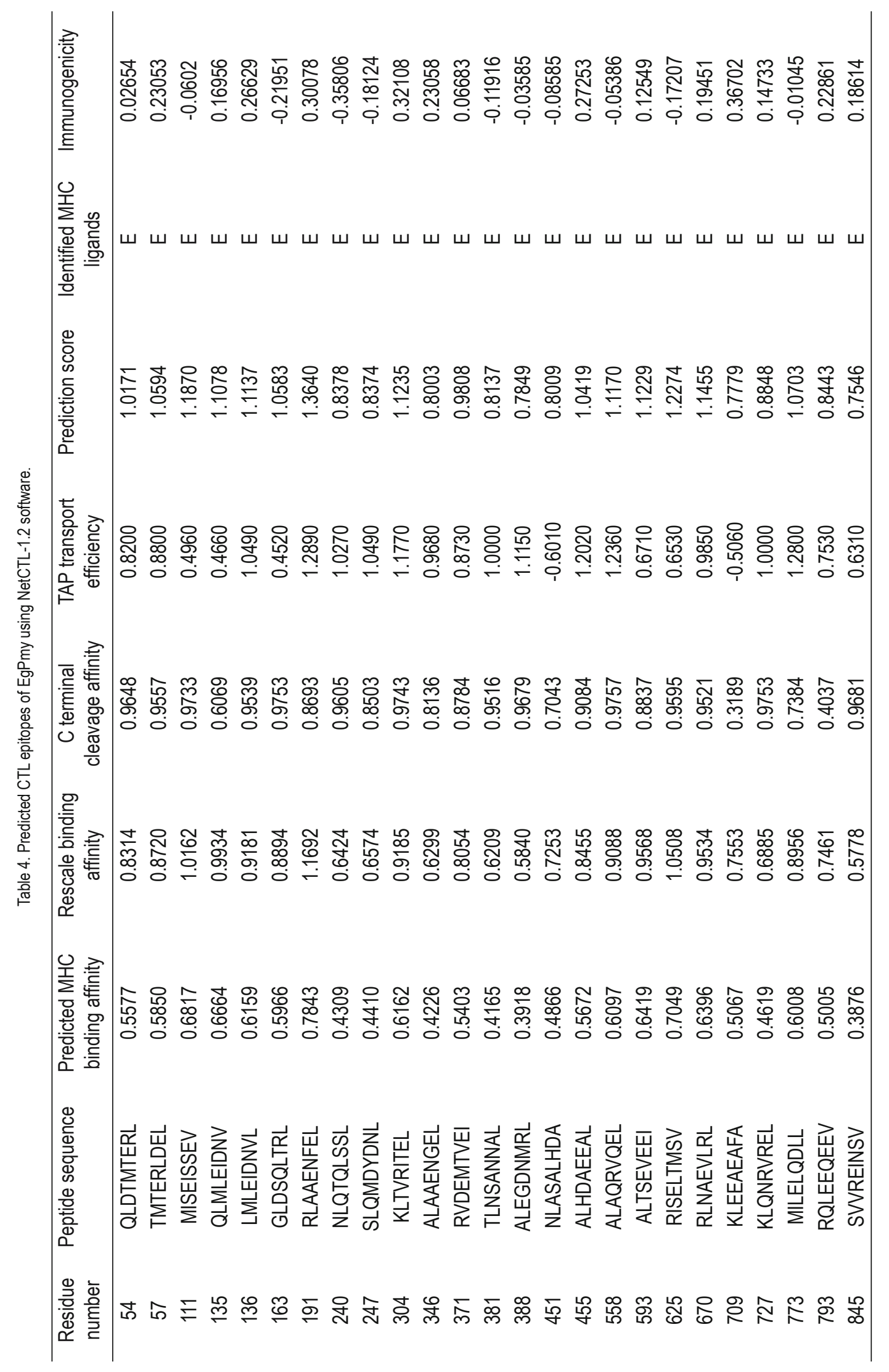




\section{CTL epitopes identification}

CTL epitopes were predicted using NetCTL.1.2 server prediction tool. Protein sequence was predicted based on their MHC binding affinity, proteasomal C-terminal cleavage, and transport affinity. Prediction was performed using MHC supertype A2. Twenty-five peptides with 9-mer sequence, whose prediction scores were over 0.75000, were identified as CTL epitopes (Shown in Table 4). Then, these peptide sequences were submitted for MHC Class I immunogenicity prediction. Most of them showed high score of immunogenicity to activate and elicit CTL's effector functions (Table 4).

\section{Discussion}

Pmy has been demonstrated to be a promising vaccine candidate for control of S. japonicum, S. mansoni (Jiz et al., 2015), Brugia malayi (Nanduri et al., 1989), T. solium (Vazquez et al.2001) and T. saginata (Ferrer et al., 2003) infections. These results implied a potential of EgPmy to be an effective vaccine against CE. In order to lay the basis for the development of the EgPmy-based epitope vaccine to control and prevent cystic echinococcosis, the in silico analysis was performed to probe the secondary structures, B-cell and CTL epitopes of the EgPmy protein.

The a-helices and extended strands are very common structures and located inside the secondary structure of proteins, which cannot be changed easily. The a-helices and extended strands accounted for $84.82 \%$ and $6.60 \%$ in EgPmy, indicating a good stability of the protein. On the contrary, the random coils and $\beta$-turns often appear on the protein surface and have the potential to form epitopes (Li et al., 2013). The proportions of the random coils and $\beta$-turns were $5.56 \%$ and $3.01 \%$ in EgPmy, respectively. These regions are likely to form epitopes.

A key process of epitope vaccine preparation is to obtain useful epitopes (Li et al., 2013). Epitopes can be divided into B- and T-cell epitopes. B-cell epitope is a binding site of an antibody on an antigen, and accurate epitope identification is essential to developing epitope vaccines (Ren et al., 2014). To improve the accuracy of the B-cell epitope prediction, multi-parameter analysis was utilized in this study. The surface accessibility area analysis showed that the residues on the surface of EgPmy, might contact with the solvent molecules. The flexibility parameter prediction reflected the ability of the protein to fold and bend and the antigenic propensity analysis demonstrated the immunogenic regions of the antigen protein (Kolaskar \& Tongaonkar, 1990; Emini et al., 1985; Vihinen et al., 1994). In this study, 29 linear B-cell epitopes were identified for EgPmy with the high antigenic property. Notably, ${ }^{754} \mathrm{RKYERQ}{ }^{759}$ and ${ }^{67} \mathrm{GTSSQTQ}{ }^{72}$ showed a high value of surface accessibility and fragment flexibility, respectively, which might suggested that the residues were the most likely vital epitopes that can be used to develop EgPmy-based epitope vaccine. However, it is worth noting that some epitopes, due to the restriction of complicated 3D structure, are shielded by the outer layer of the protein, which is called conformation epitope. This study also predicted 6 confor- mational epitopes in EgPmy. Overall, a total of 35 B-cell epitopes were found in EgPmy, which indicated a strong immunogenicity of this protein.

CTLs can destroy infected cells, and their activation takes place on the surface of antigen-presenting MHC molecules (Larsen et al., 2007). Hence, reliable prediction of CTL epitopes is a vital step for designing epitope-driven vaccine. In T-cell epitope prediction, the accuracy rate of the MHC-I epitope prediction has been demonstrated to be as high as $90 \%$ (Testa et al., 2012). However, it is restricted by human leukocyte antigen ( $\mathrm{HLA}$ ) proteins which is highly polymorphic in diverse ethnic populations (Maenaka \& Jones, 1999; Stern \& Wiley, 1994). Yan et al (2003) found that the MHC-I HLA-A*0201-restricted T-cell epitopes are common in Chinese Han people. Therefore, this study analyzed the HLA-A*0201-restricted CTL epitopes in EgPmy, and 25 high score CTL epitopes were identified, which might be of great use to develop epitope vaccine.

In conclusion, this study analyzed the secondary structure, B-cell and CTL epitopes in EgPmy. Twenty-nine linear B-cell epitopes, 6 conformation epitopes and 25 CTL epitopes were identified as the potential dominant epitopes. Moreover, the CTL epitope ${ }^{709} \mathrm{KLEE}$ $A E A F A^{717}$ showed a high potential to elicit a CTL response. Overall, the results would provide the basis for the preparation of the EgPmy-based epitope vaccine against CE.

\section{Acknowledgements}

Project support was provided, in part, by the training Programs of Innovation and Entrepreneurship for College Students in Jiangsu Province (No. 201510313017Z), the Talents Scientific Research Foundation of Xuzhou Medical University (No. D2015004), the Top-notch Academic Programs Project of Jiangsu Higher Education Institutions (PPZY2015B161), the Natural Science Foundation of the Jiangsu Higher Education Institutions (No.15KJB310025), and the Jiangsu Qing Lan Project. The funders had no role in study design, data collection and analysis, decision to publish, or preparation of the manuscript.

\section{References}

Ben, Y.T., ARnon, R. (2005): Towards an epitope-based human vaccine for influenza. Hum. Vaccin., 1(3): 95 - 101

Calis, J.J., Maybeno, M., Greenbaum, J.A., Weiskopf, D., De-Silva, A.D., Sette, A., Kesmir, C., Peters, B. (2013): Properties of MHC class I presented peptides that enhance immunogenicity. PLoS Comput. Biol., 9(10): e1003266. DOI: 10.1371/journal. pcbi.1003266

COHEN, C. (1982): Matching molecules in the catch mechanism. Proc. Natl. Acad. Sci. USA, 79: 3176 - 3178

Eckert, J., Conraths, F.J., TACKmann, K. (2000): Echinococcosis: an emerging or re-emerging zoonosis? Int. J. Parasitol., 30(12 13): $1283-1294$ 
Emini, E.A., Hughes, J.V., Perlow, D.S., Boger, J. (1985): Induction of hepatitis $A$ virus-neutralizing antibo dy by a virus-specific synthetic peptide. J. Virol., 55(3): 836-839.

Ferrer, E., Moyano, E., Benitez, L., Gonzalez, L. M., Bryce, D., Foster-Cuevas, M., Davila, L., Cortez, M.M., Harrison, L.J., Parkhouse, R.M., Garate, T. (2003): Cloning and characterization of Taenia saginata paramyosin cDNA. Parasitol. Res., 91(1): 60 - 67. DOI: $10.1007 /$ s00436-003-0895-5

Gasteiger, E., Hoogland, C., Gattiker, A., Duvaud, S.E., Wilkins, M.R., Appel, R.D., Bairoch, A. (2005): Protein identification and analysis tools on the ExPASy Server. In: WALKER, J. M. (Ed) The Proteomics Protocols Handbook. Humana Press, pp 571 - 607 GeOURJON, C., DelÉAGE, G. (1995): SOPMA: significant improvements in protein secondary structure prediction by consensus prediction from multiple alignments. Comput. Appl. Biosci., 11: 681 - 684

Gobert, G.N., Mcmanus, D.P. (2005): Update on paramyosin in parasitic worms. Parasitol. Int., 54: 101-107. DOI: 10.1016/j. parint.2005.02.004

Jiz, M.A., Wu, H., Olveda, R., Jarilla, B., KuRtis, J.D. (2015): Development of paramyosin as a vaccine candidate for schistosomiasis. Front. Immunol., 6: 347. DOI: 10.3389/fimmu.2015.00347 Катон, Y., Kouguch, H., Мatsumoto, J., Goto, A., Suzukı, T., Oku, Y., YAGI, K. (2008): Characterization of emY162 encoding an immunogenic protein cloned from an adult worm-specific cDNA library of Echinococcus multilocularis. Biochim. Biophys. Acta., 1780 (1): 1 - 6. DOI: 10.1016/j.bbagen.2007.08.020

Kolaskar, A.S., TongaOnKar, P.C. (1990): A semi-empirical method for prediction of antigenic determinants on protein antigens. FEBS Lett., 276(1 - 2): 172 - 174. DOI: 10.1016/0014-5793(90)80535-Q Kouguchi, H., Matsumoto, J., Yamano, K., Katoh, Y., OKu, Y., Suzuki, T., YAGI, K. (2011): Echinococcus multilocularis: purification and characterization of glycoprotein antigens with serodiagnostic potential for canine infection. Exp. Parasitol., 128 (1): 50 - 56. DOI: 10.1016/j.exppara.2011.02.002

KYtE, J., DoolitTlE, R.F. (1982): A simple method for displaying the hydropathic character of a protein. J. Mol. Biol., 157(1): 105 - 132. DOI: 10.1016/0022-2836(82)90515-0

Larsen, M.V., Lundegaard, C., Lamberth, K., Buus, S., Lund, O., NiELSEN, M. (2007): Large-scale validation of methods for cytotoxic T-lymphocyte epitope prediction. BMC Bioinformatics, 8: 424. DOI: 10.1186/1471-2105-8-424

Li, Y., Liu, X., Zhu, Y., Zhou, X., CaO, C., Hu, X., Ma, H., Wen, H., Ma, X., DIND, J. B. (2013): Bioinformatic prediction of epitopes in the Emy162 antigen of Echinococcus multilocularis. Exp. Ther. Med., 6(2): 335 - 340. DOI: 10.3892/etm.2013.1142

Lightowlers, M. W., Lawrence, S. B., Gaucl, C. G., Young, J., RalSton, M.J., MAas, D., HEATH, D.D. (1996): Vaccination against hydatidosis using a defined recombinant antigen. Parasite Immunol., 18 (9): 457 - 462. DOI: 10.1111/j.1365-3024.1996.tb01029.x

MAENAKA, K., Jones, E.Y. (1999): MHC superfamily structure and the immune system. Curr. Opin. Struct. Biol., 9(6): 745-753. DOI: 10.1016/S0959-440X(99)00039-1
Moghadam, Z.K., Ghaffarifar, F., Khalilpour, A., Abdul-Aziz, F., SAAdATNIA, G., NoORDIN, R. (2013): IgG4 detection of Echinococcus granulosus paramyosin is a useful diagnostic test for human hydatidosis. Clin. Vaccine Immunol., 20(4): 501 - 505. DOI: 10.1128/ CVI.00019-13

Monteiro, K.M., De-Carvalho, M.O., Zaha, A., Ferreira, H.B. (2010): Proteomic analysis of the Echinococcus granulosus metacestode during infection of its intermediate host. Proteomics, 10(10): 1985 - 1999. DOI: 10.1002/pmic.200900506

Mühlschlegel, F., Sygulla, L., Frosch, P., Massetti, P., Frosch, M. (1993): Paramyosin of Echinococcus granulosus: cDNA sequence and characterization of a tegumental antigen. Parasitol. Res., 79(8): 660 - 666. DOI: 10.1007/BF00932508

NANDURI, J., KazURA, J.W. (1989): Paramyosin-enhanced clearance of Brugia malayi microfilaremia in mice. J. Immunol., 143(10): $3359-3363$

Nasrieh, M.A., Abdel-Hafez, S.K., Kamhawi, S.A., Craig, P.S., SchanTz, P.M. (2003): Cystic echinococcosis in Jordan: socioeconomic evaluation and risk factors. Parasitol. Res., 90 (6): 456 466. DOI: $10.1007 / \mathrm{s} 00436-003-0883-9$

Nunnari, G., Pinzone, M. R., Gruttadauria, S., Celesia, B. M., Madeddu, G., Malaguarnera, G., Pavone, P., Cappellani, A., CacoPARDO, B. (2012): Hepatic echinococcosis: clinical and therapeutic aspects. World J. Gastroenterol., 18(13): 1448 - 1458. DOI: 10.3748/wjg.v18.i13.1448

OyarzúN, P., Kobe, B. (2016): Recombinant and epitope-based vaccines on the road to the market and implications for vaccine design and production. Hum. Vaccin. Immunother., 12(3): 763 767. DOI: 10.1080/21645515.2015.1094595

Petavy, A.F., Hormaeche, C., Lahmar, S., Ouhelli, H., Chabalgoity, A., Marchal, T., Azzouz, S., Schreiber, F., Alvite, G., Sarciron, M. E., Maskell, D., Esteves, A., Bosquet, G. (2008): An Oral Recombinant Vaccine in Dogs against Echinococcus granulosus, the Causative Agent of Human Hydatid Disease: A Pilot Study. PLoS Negl. Trop. Dis., 2(1): e125. DOI: 10.1371/journal.pntd.0000125

Pfaff, E., Thiel, H.J., Beck, E., Strohmaier, K., Schaller, H. (1988): Analysis of neutralizing epitopes on foot-and-mouth disease virus. J. Virol., 62(6): 2033 - 2040

Ponomarenko, J., Bui, H.H., Li, W., Fusseder, N., Bourne, P.E., Sette, A., Peters, B. (2008): ElliPro: a new structure-based tool for the prediction of antibody epitopes. BMC bioinformatics, 9: 514 . DOI: 10.1186/1471-2105-9-514

REN, J., LIU, Q., ELLIS, J., LI, J. (2014): Tertiary structure-based prediction of conformational B-cell epitopes through B factors. Bioinformatics, 30(12): i264 - 273. DOI: 10.1093/bioinformatics/btu281 Siles-Lucas, M., Merli, M., Mackenstedt, U., Gottstein, B. (2003): The Echinococcus multilocularis 14-3-3 protein protects mice against primary but not secondary alveolar echinococcosis. Vaccine, 21 (5 - 6): 431 - 439. DOI: 10.1016/S0264-410X(02)00517-0 SteRN, L.J., WILEY, D.C. (1994): Antigenic peptide binding by class I and class II histocompatibility proteins. Structure, 2(4): 245 - 251. DOI: 10.1016/S0969-2126(00)00026-5 
Testa, J.S., Shetty, V., Hafner, J., Nickens, Z., Kamal, S., SinnathambY, G., PhILIP, R. (2012): MHC class I-presented T cell epitopes identified by immunoproteomics analysis are targets for a cross reactive influenza-specific T cell response. PLoS One, 7(11): e48484. DOI: 10.1371/journal.pone.0048484

TOUSSAINT, N.C., KoHlBACher, O. (2009): Towards in silico design of epitope-based vaccines. Expert Opin. Drug Discov., 4(10): 1047 1060. DOI: 10.1517/17460440903242283

Vazquez-Talavera, J., Solis C.F., Terras L.I., Laclette J.P. (2001): Characterization and protective potential of the immune response to Taenia solium paramyosin in a murine model of cysticercosis. Infect. Immun., 69(9): 5412 - 5416. DOI: 10.1128/IAI.69.9.54125416.2001

VIHINEN, M., TORKKILA, E., RIIKONEn, P. (1994): Accuracy of protein flexibility predictions. Proteins, 19(2): 141-149. DOI: 10.1002/ prot.340190207

Vita, R., Zarebski, L., Greenbaum, J.A., Emami, H., Hoof, L., Salimi, N., Damle, R., Sette, A., Peters, B. (2010): The Immune Epitope
Database 2.0. Nucleic Acids Research, 38: D854 - 862. DOI: 10.1093/nar/gkp1004

Yan, C., Wang, R., Li, J., Deng, Y., Wu, D., Zhang, H., Wang, L., Zhang, C., Sun, H., Zhang, X., Wang, J., Yang, H., LI, S. (2003): HLA-A gene polymorphism defined by high-resolution sequence-based typing in 161 Northern Chinese Han people. Gen. Prot. Bioinform., 1: 304 - 309. DOI: 10.1016/S1672-0229(03)01036-2

Yang, S., Wu, W., Tian, T., Zhao, J., Chen, K., Wang, Q., Feng, Z. (2015): Prevalence of Cystic Echinococcosis in Slaughtered Sheep as an Indicator to Assess Control Progress in Emin County, Xinjiang, China. Korean J. Parasitol., 53(3): 355 - 359. DOI: 10.3347/kjp.2015.53.3.355

Zieglmayer, P., Focke-Tejkl, M., Schmutz, R., Lemell, P., Zieglmayer, R., Weber, M., Kiss, R., Blatt, K., Valent, P., Stolz, F., Huber, H., Neubauer, A., Knoll, A., Horak, F., Henning, R., Valenta, R. (2016): Mechanisms, safety and efficacy of a $B$ cell epitope-based vaccine for immunotherapy of grass pollen allergy. EBioMedicine, 11: $43-$ 57. DOI: 10.1016/j.ebiom.2016.08.022

Supplementary Figs. 1 - 4 are available online at https://doi.org/10.1515/helm-2017-0041. 